\title{
A VOZ QUE VEM DA PERIFERIA: O JOVEM E SUAS NARRATIVAS PERCEBIDAS NA PUBLICIZAÇÃO DE IMAGENS E POSTAGENS NAS REDES SOCIAIS
}

\section{THE VOICE WHICH COMES FROM THE PERIPHERY: THE YOUTH AND ITS NARRATIVES VIEWED ON IMAGES IN SOCIAL NETWORKS}

\author{
Ricardo Oliveira de Freitas ${ }^{1}$ \\ Cíntia Sacramento do Espírito Santo ${ }^{2}$
}

Resumo: As tecnologias digitais da informação e comunicação estão presentes em quase todos os espaços de convivência cotidiana, fazendo parte da rotina dos indivíduos. Ao pesquisar o protagonismo dos jovens da periferia de Salvador na cena digital, o trabalho abordou as narrativas desses jovens a fim de identificar traços que apontem sentimento de pertença às comunidades em que residem. Foi possível perceber que os jovens utilizam a rede social para reclamar de problemas situacionais; propagar atividades de cunho político e social e, sobretudo, fazer reverberar a emergência de um olhar menos preconceituoso em relação à periferia e aos seus moradores.

Palavras-chave: Jovens da periferia. Representações de si. Redes sociais e Dispositivo.

Abstract: The information and communication technologies are present in almost all social interaction spaces. They are also part of people's daily lives. This research analysed the role of youth in the outskirts of Salvador in the digital scene, addressing in their narratives the feeling of belonging to the communities where they live. We observed that the youth use the social network to claim about some situational problems; related to the negative representations about the periphery and its residents.

Keywords: Youth. Periphery. Self Representations. Social networks and Device.

\footnotetext{
${ }^{1}$ Universidade do Estado da Bahia (UNEB), Salvador, Doutor em Comunicação e Cultura (UFRJ), Professor Titular. E-mail: ricofrei@gmail.com

${ }^{2}$ Universidade do Estado da Bahia (UNEB), Salvador, Mestre em Crítica Cultural, Jornalista. E-mail: cintiacsj@ hotmail.com
} 


\section{INTRODUÇÃO}

Este artigo resulta da pesquisa que originou a dissertação defendida no Programa de Mestrado em Crítica Cultural, da UNEB, na qual foram analisados perfis de jovens em redes sociais, entre homens e mulheres, envolvidos em movimentos que discutem problemas sociais de minorias sociais estigmatizadas e discriminadas, dentro e fora do espaço virtual. As narrativas de si apresentadas neste artigo foram extraídas dos perfis de seis jovens - três mulheres e três homens - entre 18 e 29 anos de idade.

Destacando o protagonismo dos jovens da periferia de Salvador na cena digital - as narrativas dispostas nas redes sociais e as motivações que fazem ascender subjetividades em cada nova publicação de textos e imagens construídas em framers nas páginas pessoais do Facebook -, este trabalho analisa publicações feitas durante o auge das manifestações do Brasil, período bastante fecundo, no ano de 2013. O recorte deve-se à grande mobilização que as manifestações de rua causaram nas mídias sociais.

As análises dos perfis ora apresentados foram feitas com base nos métodos de pesquisa para internet. A etnografia virtual, também chamada de netnografia ${ }^{3}$, propõe analisar indivíduos e grupos que utilizam a internet como um lugar ou como um modo de ser, o que permite a transferência de métodos etnográficos para a pesquisa na internet e para o estudo das formas de comunicação e de autoapresentação na internet (UWE, 2009).

Oriunda do método etnográfico antropológico cuja fundamentação é a observação a partir da inserção do pesquisador em comunidades de pesquisa, a etnografia virtual, segundo Hine citada por Amaral (2008), é a metodologia ideal para iniciar os estudos sobre os diferentes usos da plataforma digital, pois serve para explorar as complexas relações existentes entre as afirmações previsíveis das novas tecnologias em diferentes contextos, como jogos, espaços de trabalho, meios de comunicação de massa, etc.

Os processos de subjetivação que ocorrem nos canais digitais a partir das narrativas dos jovens da periferia e os modos como os sujeitos sociais têm se apresentado perante múlti-

\footnotetext{
3 O neologismo "netnografia" (nethnography = net + ethnography) foi originalmente cunhado por um grupo de pesquisadores, em 1995, para descrever um desafio metodológico: preservar os detalhes ricos da observação em campo etnográfico usando o meio eletrônico. O termo netnografia tem sido mais amplamente utilizado pelos pesquisadores da área do marketing e da administração enquanto o termo etnografia virtual é mais utilizado pelos pesquisadores da área da antropologia e das ciências sociais. Como apresentam as mesmas características, são colocados como sinônimos. (AMARAL, 2008, p. 34).
} 
plos olhares em busca de reconhecimento demonstram o comportamento exibicionista desses sujeitos que clamam por atenção e legitimação, além de estarem guiados por um tom narcisista, em que a associação com os media, bem como a visibilidade implicada nos próprios meios, possibilita a produção de sentido sobre si mesmos.

O interesse em mapear os processos subjetivos que se configuram nas redes sociais, não foi apenas o desejo de fazer uma história dos mesmos, mas principalmente dar visibilidade à problemática que envolve os usos e a reprodutibilidade nesse espaço. Assim, ao se trabalhar diretamente com os jovens que utilizam as redes sociais, a partir de uma leitura de multiplicidades, será possível focalizar elementos normalmente desprezados numa análise apenas das redes.

A produção de espetáculos de si direciona os holofotes para o protagonista da performance social, o eu, visando iluminar partes da vida íntima que outrora estavam relegadas à penumbra, à intimidade, beirando os limites não mais tão precisos e estanques da publicidade e da privacidade totais. $\mathrm{O}$ conceito de performance considerado é o apresentado por Erving Goffman (1985) que relaciona metaforicamente a representação do indivíduo em sociedade a uma encenação teatral onde os elementos do atuar estão presentes para o sucesso da sua interação com a plateia.

Neste sentido, foi estabelecido um diálogo com o autor de forma a contribuir com as discussões acerca das imagens expostas de si que intencionam o olhar e reciprocidade do outro, direcionando à conjunção de peças fundamentais no processo de subjetivação de si. $\mathrm{O}$ efeito que as publicações irão gerar dependerá, entretanto, dos olhos de quem vê e das táticas utilizadas pelos jovens no jogo da encenação de forma a captar a atenção da plateia.

\section{1 - A PERIFERIA NO DESTERRITORIALIZADO ESPAÇO VIRTUAL}

Ao se pensar em periferia, muitas vezes desconsideramos o conceito geográfico e partimos para o seu sentido sociocultural, carregado de estereótipos e preconceitos como limites identificatórios. A periferia, ora apresentada neste artigo, não é a identificada hegemonicamente, mas a apresentada através das mídias digitais pelos jovens que nela vivem. Os seus 
olhares em forma de texto e imagens contribuem para (des)construir o juízo apressado que fazemos ao se falar sobre periferia.

Através da internet, e do acesso às novas tecnologias, os moradores da periferia passaram a difundir suas vozes e a apresentar uma periferia desconhecida por quem não convive nesse espaço. Os jovens são os principais responsáveis pela desmistificação desse espaço como o lugar da pobreza e dos silenciados. Abertos a novos aprendizados, os jovens apoderamse dos conhecimentos sobre os usos da tecnologia a seu favor e dentro das suas possibilidades, visibilizando-se.

Ao traduzirmos a idéia de visibilidade como a dinâmica de pertencimento a uma esfera pública constituída e concretizada nos e pelos meios de comunicação, que caracterizam esta como uma sociedade midiática, logo, entendese que estar invisível revela "não estar nos meios" e, com trocadilhos, "nem estar no meio". É, pois, estar na base e não na ponta (FREITAS, 2007).

As "minorias" que ocupam os espaços periféricos são colocadas numa posição de vitimização que, muitas vezes, não lhes cabe. Conhecedores da sua condição, os jovens sabem o que pretendem transmitir através dos posicionamentos que adotam no espaço virtual. Há neles um sentimento de pertença e, contraditoriamente, de recusa ao lugar onde vivem que deixa escapar uma vontade de mudança e em torná-lo conhecido para além do que é apresentado pelas grandes mídias e pelo poder hegemônico.

Além de morarem na periferia, os jovens têm em comum o sentimento de pertença à comunidade em que se encontram. Suas iniciativas sociais estão em possibilitar um olhar diferenciado tanto por quem mora nos bairros periféricos como por quem desconhece totalmente esta realidade. Distribuídos pelos bairros: Sussuarana, Nordeste de Amaralina, Liberdade e Cajazeiras, os jovens pesquisados encontram formas diferenciadas de repercussão de notícias e/ou ações para esses bairros, alguns possibilitam que as ações de estendam a outras comunidades que enfrentam as mesmas privações a fim de mudar a perspectiva sobre as periferias de Salvador.

Interatividade e consumo são grandes plataformas de discussões e análises sobre a emergência na ampliação do mercado tecnológico da informação de comunicação. Contudo, o debate acerca da desigualdade social no que tange o uso que se faz da internet por classes distintas ainda se apresenta de forma preconceituosa por analistas e pesquisadores. Obviamente 
que é preciso relativizar, mas é possível perceber que o lugar dos sujeitos de classes populares é colocado à margem também no ciberespaço. Além das constantes críticas em fóruns, redes sociais, blogs e meios afins sobre a postura das pessoas de classes populares na internet, há ainda a percepção de que as práticas sociais oportunizaram formas ilícitas de conectividade por esses sujeitos, sobretudo a juventude, diante da impossibilidade financeira para uma participação legal.

O discurso dos jovens da periferia em outros espaços midiáticos é silenciado, pois na lógica comunicacional a voz que vigora são aquelas condicionadas a atender as expectativas e interesses do poder institucional. Esta ação, segundo Foucault (1996), é uma estratégia de exclusão a fim de evitar que discursos perigosos se proliferem indefinidamente. Através do que postam nas redes sociais os jovens se fazem ouvir e externam suas opiniões e pensamentos, sem que para isso necessitem de alguma instituição para lhe conceder o poder de manifestar-se.

Apropriando-se do espaço virtual, os jovens da periferia fazem ecoar sua realidade de acordo com as significações contextuais e as relações que estabelecem dentro e fora das redes. A vontade em tornar conhecido o lugar onde vivem com os mesmos olhares que têm demonstra o desejo em apresentar uma periferia por vezes desconhecida, mas sobretudo, em mostrar que eles também são a diferença.

Através dessas iniciativas e práticas de acessibilidade atuais, onde as barreiras sociais por vezes são acortinadas, mas que ainda assim permitem a integração, que as redes sociais se fazem desterritorializadas. É a desterritorialização em rede que permitirá o fluxo de conhecimentos beneficiando todos que desconhecem outras realidades, culturas ou saberes. É a circulação livre, a acessibilidade ilimitada que justapõe conhecimentos de qualquer ordem.

De acordo com Deleuze e Guatarri a desterritorialização surge para dar conta de uma noção com pretensão nova. A noção com pretensão nova de que nos fala os autores "é que não há território sem um vetor de saída do território, e não há saída do território, ou seja, desterritorialização, sem, ao mesmo tempo, um esforço para se reterritorializar em outra parte" (DELEUZE apud HAESBAERT, 2013, p.1). Os conceitos Deleuze-guatarrinianos apresentam-se de forma múltipla, num desdobrar que não permite apreensão e enquadramento, características pertinentes às discussões sobre espaços, fronteiras, territórios e suas ausências, so- 
bretudo no ciberespaço, e que oportunizam pensar o conceito no contexto atual, dentro e fora do espaço virtual.

\begin{abstract}
A espécie humana está mergulhada num imenso movimento de desterritorialização, no sentido de que seus territórios "originais" se desfazem ininterruptamente com a divisão social do trabalho, com a ação dos deuses universais que ultrapassam os quadros da tribo e da etnia, com os sistemas maquínicos que a levam a atravessar cada vez mais rapidamente, as estratificações materiais e mentais (GUATTARI e ROLNIK, 1986, p. 323).
\end{abstract}

Muitos autores defendem a tese de que a desterritorialização é uma característica da sociedade contemporânea, dominada pela mobilidade, pelos fluxos, pelo desenraizamento e pelo hibridismo cultural. A "sociedade em rede" (CASTELLS, 1999) é fluida e desterritorializada, na medida em que ela aparece sempre conjugada com a reconstrução de territórios, ainda que territórios mais móveis e descontínuos.

A internet, e por extensão as redes sociais, tornam-se o espaço em que os desejos extrapolam, em que virtual não serve apenas para denominar a internet, mas se estende aos seus usuários e suas ações aparentemente materializadas. Nas redes sociais, atualmente, a apropriação do espaço/território ocorre de forma deliberada por pessoas de qualquer camada social. O lugar antes restrito às mais altas classes, hoje traz para o cerne da sua rede toda a margem, deixando-a sem bordas de distinção, sem hierarquia, descentralizada e relativizada.

Nas mídias sociais, é comum entre os jovens todo tipo de narrativa, sobretudo aquelas relacionas às situações cotidianas. Isto não é categorizado por classes. Não é uma ação privilegiada. A vontade em gerar notificações encontra-se em qualquer espaço e simboliza um reconhecimento sobre os posts publicados. As participações e ações que desenvolvem junto às periferias que moram, fazem parte do cotidiano dos jovens da pesquisa, e assim como tantas outras atividades que exercem, estas ficam a olhos vistos no feed de notícias dos contatos relacionados.

Pode-se parecer um enaltecimento das periferias como um lugar merecedor do reconhecimento criativo e cultural em comparação a outros espaços, mas não é este o mérito que os jovens querem destacar do lugar onde moram. O que a maioria busca é simplesmente que seu espaço seja visto na sua diversidade, nas suas potencialidades e também nos seus proble- 
Pontos de Interrogação, v. 4, n. 1, jan./jun. 2014

Revista do Programa de Pós-Graduação em Crítica Cultural

Universidade do Estado da Bahia (UNEB), Campus II - Alagoinhas - BA

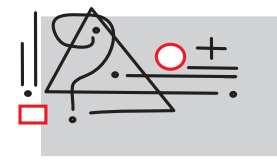

pontos de interrogação

mas, livres das amarras preconceituosas impostas pela mídia e perpetuadas no imaginário coletivo hegemônico.

A expansão e visibilidade que os jovens conquistaram nos seus perfis se devem a um trabalho de relação que antecede a criação da própria página na rede social. Se hoje eles têm em média quase mil contatos é resultado dos trabalhos que desenvolvem em suas comunidades e propagados através das fanpages e outras mídias sociais. Um trabalho cuja repercussão se faz por meio de palestras, cursos, matérias jornalísticas e tantas outras formas de expressão que dimensionam suas atividades e, por conseguinte, a própria figura executora, como demonstrado nas imagens abaixo. Essa expansão ultrapassa fronteiras territoriais, ocupando espaços antes restritos, ascendendo o que antes era invisibilizado.
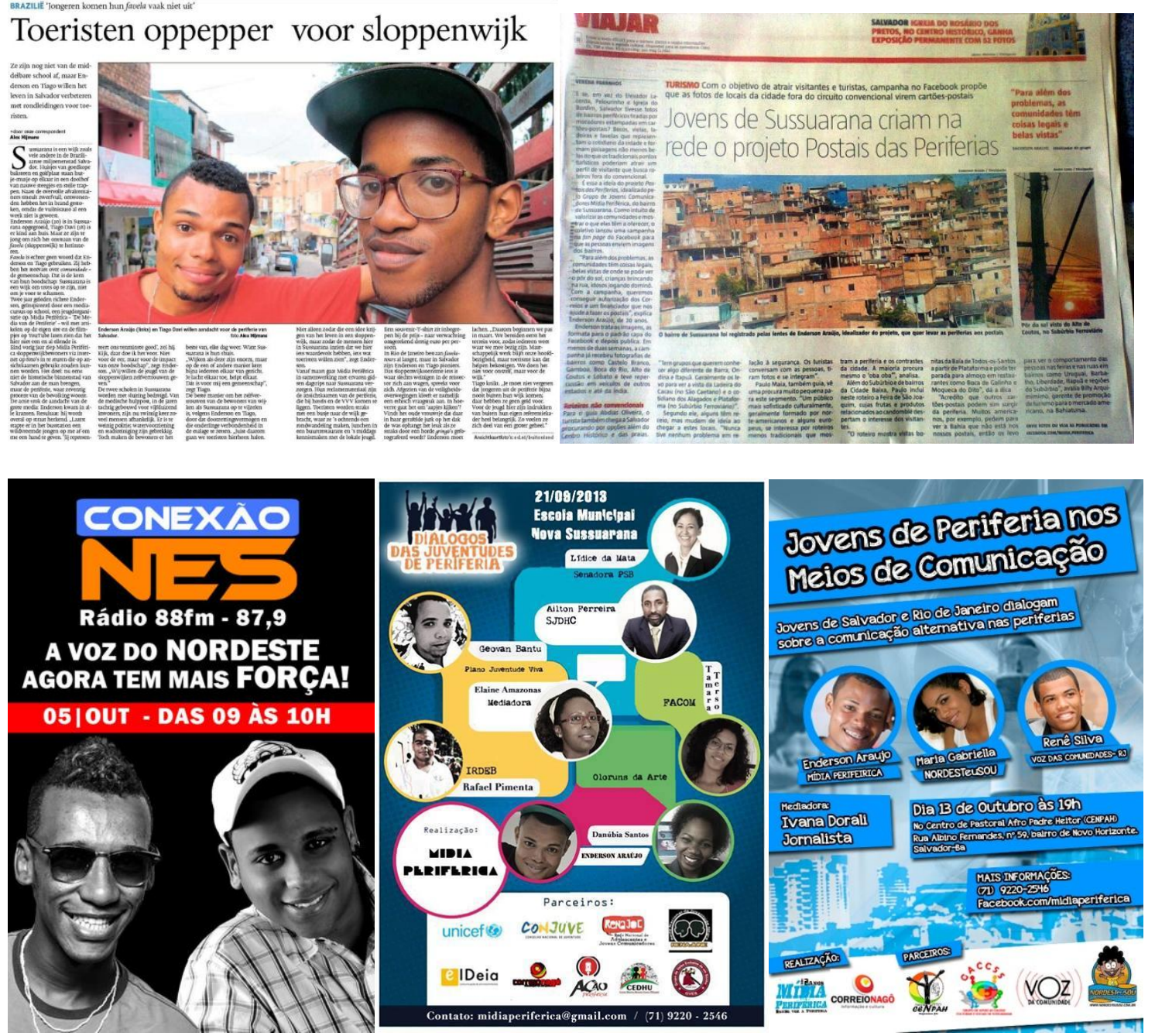
"O paradigma tradicional colocava o sujeito como passivo e espectador do mundo, agora estamos à frente de um sujeito-coletivo que busca a remoção das fronteiras e a desterritorialização do conhecimento" (BRETHERICK, 2010, p.187). No entanto, a engrenagem que move as redes sociais; vontade do saber, do conhecimento, gera um autodidatismo que é proporcionado pela internet como um todo. O que move as redes sociais é a repercussão de si por meio da sua representação mais atraente e crível.

\section{2- REDE SOCIAL COMO DISPOSITIVO: TÁTICAS NARRATIVAS NA PRODUÇÃO DE SUBJETIVIDADES}

Nunca estivemos tão expostos e, contraditoriamente, ansiando por esta exposição. Diante deste comportamento contemporâneo, empresas de tecnologia da informação e comunicação criam a todo o momento, aparelhos, softwares, aplicativos e ferramentas que pululam em nossos olhos a cada vez que acessamos a internet. Tecnologias que têm na fotografia o chamariz para aquisição. Grande parte da tecnologia investida nas novas tecnologias concentra-se na melhoria e qualidade das imagens registradas, seja na manipulação ou na propagação, resultando naquilo que Jenkins (2008) denomina de convergência.

Por convergência refiro-me ao fluxo de conteúdos através de múltiplos suportes midiáticos, a cooperação entre múltiplos mercados midiáticos e o comportamento migratório dos públicos dos meios de comunicação, que vão a quase qualquer parte em busca das experiências de entretenimento que desejam (p. 27).

O espaço virtual de tão público ultrapassou a fronteira do privado, ou será que os usuários é que não permitem mais estar no anonimato? A internet, esse "universo não totalizável" (LEVY, 1999) não encontra nem estabelece limites para exposição de si, ao contrário, sua imensidão a incita. Achamos normal nos vermos nos canais de comunicação digital.

O ambiente virtual é um exemplo providencial de serialização dos acontecimentos manifestos no mundo contemporâneo. O indivíduo que utiliza a plataforma digital criando um canal de comunicação e interação onde se coloca como figura central, busca de certa maneira difundir sua voz a um coletivo flutuante. As redes sociais surgem como o canal em que cada indivíduo adquire poder de fala a um público que de certa forma ele acaba por escolher. Essas 
redes seriam, portanto, um dispositivo (FOUCAULT apud AGAMBEN, 2009) que atua no processo de subjetivação dos sujeitos. Sujeito esse, que, de acordo com Giorgio Agamben (2009), seria o resultado da relação e, por assim dizer, do corpo a corpo entre os viventes e os dispositivos.

O termo dispositivo não foi definido por Foucault em suas obras, mas a palavra é recorrente em seus pensamentos. O conceito abordado é o cunhado por Foucault numa entrevista concedida em 1977 e encontra-se na obra de Agamben (2009):

Aquilo que procuro individualizar com este nome (dispositivo) é, antes de tudo, um conjunto absolutamente heterogêneo que implica (...) tanto o dito como o não dito, eis os elementos do dispositivo. O dispositivo é a rede que se estabelece entre estes elementos. Com o termo dispositivo, compreendo uma espécie - por assim dizer - de formação que num certo momento histórico teve como função essencial responder a uma urgência. $\mathrm{O}$ dispositivo tem, portanto, uma função eminentemente estratégica [...] Disse que o dispositivo tem natureza essencialmente estratégica, que se trata, como consequência, de uma certa manipulação de relações de força, de uma intervenção racional e combinada das relação de força seja para orientá-las em certa direção, seja para bloqueá-las ou para fixá-las e utilizá-las. O dispositivo está sempre inscrito num jogo de poder e, ao mesmo tempo, sempre ligados aos limites do saber, que derivam desse e, na mesma medida, condicionam-no.

O conceito de dispositivo torna-se apropriado neste trabalho cujo cerne é o sujeito em meio à rede social, e as relações que ali se estabelecem onde estão imbricados elementos discursivos e não discursivos; estratégias de poder e enquadramento do meio técnico e táticas de fuga dos usuários diante das limitações impostas. Assim sendo, o que está evidenciado pelos jovens em seus perfis coloca-se como análise do campo discursivo enquanto o não-dito se faz presente nas táticas mal sucedidas que resultam em poucas, ou quase nenhuma, interação frente ao exposto nas redes sociais e nas limitações técnicas do próprio dispositivo.

O conceito de Foucault aponta para a ideia de controle social intrínseco aos dispositivos. Tangenciando, portanto, para uma percepção de que as redes sociais são indiscutivelmente o lugar em que as relações sociais se estabelecem de forma diferenciada do real. As redes não estão diretamente vinculadas às amarras sociais que se configuram fora do virtual, porém não deixam de ser vigilantes no ambiente em que se estabelece. 
Iludido pela possibilidade de expressão livre, o indivíduo utiliza as redes sociais como o lugar do confessional. Elas ensejam atualizações que não cessam de crescer. O excesso de informações nos canai s de compartilhamento implica numa participação efetiva do ator social que busca reluzir seu perfil. Motivado pela vontade em se fazer ver e ouvir, as publicações feitas por ele são, muitas vezes, alterdirigidas. Este tipo de relação é a principal funcionalidade do espaço que é concebido visando à participação do outro.

Quando se faz parte de uma sociedade, a reciprocidade é fundamental para que as relações se estabeleçam de forma eficiente e que possa obter um diálogo e entendimento com menos ruído possível. Segundo Goffman (1985) a recíproca é necessária também para a eficácia da representação do indivíduo diante do grupo.

Seja o que for que crie o desejo humano de contato e companheirismo social, o efeito parece tomar duas formas: a necessidade de um público diante do qual pôr à prova a própria personalidade jactanciosa e a necessidade de companheirismos de equipe, com os quais se possa entrar em intimidades coniventes e praticar o descontraimento dos bastidores. (p. 189).

Nas redes sociais a necessidade de cumplicidade social é bastante presente e fundamental para o fim de uma convivência idealizada por todos que compõem o ambiente virtual. Mesmo quando a resposta não atende as expectativas do estímulo, ainda assim, ela consegue de alguma forma criar espaços para a interação.

No geral, a participação das pessoas nas publicações dos jovens envolvidos na pesquisa atende a uma expectativa comum nas redes sociais. Quando alguma notificação foge do esperado (leia-se divergente e agressiva) a postura dos jovens é ignorar ou explicar a publicação que difundiu a celeuma virtual. Num espaço em que pessoas desconhecidas são classificadas como amigas, a sujeição a riscos e desavenças é iminente.

$\mathrm{Na}$ rede social cada perfil torna-se autobiográfico, com narrativas fragmentadas da vida de cada indivíduo, gerando transgressão na escrita corroborada por todos. Trechos do cotidiano são compartilhados, muitas vezes, através de frases curtas e fotografias. As biografias criadas nos perfis das redes sociais, contudo, são polissêmicas, isto é, vozes de outros sujeitos contidas nos comentários e curtidas dos posts convergem para a criação do si. 
Os acontecimentos atualizados a todo instante pelos usuários das redes sociais, permitem uma multiplicidade de sentidos ao passo que são conceituados sob diversos pontos de vista. Por outro lado, estes múltiplos olhares que permeiam as redes sociais não fixam sentidos totalizantes por estarem num espaço de renovação constante. Igualmente, as redes sociais permitem aos próprios atores sociais, nesse caso os marginalizados, construírem suas histórias fazendo ecoar vozes outrora silenciadas, de forma a permitir o deslocamento para que outras possibilidades se tornem visíveis e subjetividades criadas.

De acordo com Sibilia (2008), há três perspectivas que delimitam a subjetividade do indivíduo. A primeira se refere ao nível singular, cuja análise focaliza a trajetória de cada indivíduo como sujeito único e irrepetível. Do outro lado estaria a análise universal da subjetividade que abrange todas as características comuns ao gênero humano. E entre essas duas análises encontra-se a denominada particular e universal que detecta elementos comuns a alguns sujeitos, mas não necessariamente inerente a todos os seres humanos. Diante destas três perspectivas, este capítulo parte da terceira análise cuja subjetividade está localizada entre os níveis singular e universal da experiência, ou seja, aspectos subjetivos que são claramente culturais que impulsionam o surgimento de certas formas de ser e estar no mundo.

Reforçando a terceira perspectiva de Sibilia e para a melhor compreensão de subjetividade adotada, trago a noção de Deleuze e Guatarri (1985) que desconstroem a ideia de sujeito único, estável e centralizado apresentando-se como sujeito instável, composta por diversas multiplicidades. Tais multiplicidades são conectadas por agenciamentos responsáveis pelo processo de subjetivação. Conexões que se formam por meio de redes e forças sociais que atuam sobre elas.

Através do que postam nas redes sociais os jovens se fazem ouvir e externam suas opiniões e pensamentos, sem que para isso necessitem de alguma instituição para lhe conceder o poder de manifestar-se (FOUCAULT, 1996). O protagonismo dos jovens analisados, no espaço digital se dá, portanto, pelas questões sociais debatidas. Informes de debates também geram notificações e interesse por parte dos seus pares. São construídas narrativas nãolineares serializadas pelos seus postulantes

O discurso dos indivíduos da periferia, sobretudo dos jovens, em outros espaços midiáticos é silenciado, pois na lógica comunicacional a voz que vigora são aquelas condiciona- 
das a atender as expectativas e interesses do poder institucional. Esta ação, segundo Foucault (1996), é uma estratégia de exclusão a fim de evitar que discursos perigosos se proliferem indefinidamente. Ainda de acordo com Foucault o que há de perigoso em as pessoas falarem é que

Em toda sociedade a produção do discurso é ao mesmo tempo controlada, selecionada, organizada e redistribuída por certo número de procedimentos que têm por função conjurar seus poderes e perigos, dominar seu acontecimento aleatório, esquivar sua pesada e temível materialidade. (p. 8-9).

O narrador, nesta nova roupagem, ressurge como um contador de histórias da sua própria vida. Benjamin (1994), no entanto, observou que a figura do narrador havia deixado de existir. Segundo ele, a motivação para este fenômeno seria a falta de ações da experiência ocasionada pela situação de guerra. "No final da guerra, observou-se que os combatentes voltavam mudos do campo de batalha não mais ricos, e sim mais pobres em experiência comunicável” (p.198). Além disso, o surgimento do romance e a difusão da informação também seriam responsáveis pelo declínio da narrativa. Para ele, narrar ocorre na transmissão de experiência de pessoa para pessoa e, portanto, os melhores narradores estariam divididos em dois grupos: aqueles que viajam e têm muito a relatar, e também no sujeito que nunca saiu do seu país, mas conhece a história local e suas tradições.

Embora a maioria dos narradores digitais contemporâneos pouco relate a história do local onde vive, as ações práticas de vida não cessam de ser relatadas nas mídias digitais. Apropriando-se do que Benjamin considerou como característica dos narradores no início do século XX: “o senso prático é uma das características de muitos narradores” (p. 199), é possível afirmar, mesmo que de forma simplória que os narradores digitais têm como característica preponderante os relatos de experiências, histórias de vida, modos de ser, que vão se configurando em narrativas ajustadas em cada meio digital de acordo com sua política e necessidade. Atualmente, a transmissão oral é decodificada em bits para ser difundida.

O conceito de narrativa aqui tratado é o da concepção contemporânea que se movimenta longe dos entendimentos de texto narrativo como uma gramática estrutural ou como objetos sólidos no mundo. A narratologia contemporânea se apoia na visão de que as narrativas são invenções construídas em números narratológicos quase infinitos (CARNEIRO \& 
MATTES, 2013). Segundo os autores, esta noção de narratologia sintetiza pensamentos da filosofia, da linguística e da teoria literária conhecidos como teoria pós-moderna e pósmodernismo.

\begin{abstract}
A diferença cultural se tornou mais explícita com o processo de globalização que se acelera no início do século XX. Este fenômeno põe em questionamento as grandes narrativas (LYOTARD, 1998), ideológicas e literárias. Aqui, tanto a concepção iluminista (sujeito centrado, individualizado, consciente, racional, autônomo e auto-suficiente) como a noção de modernidade (sujeito discursivo e dialógico) entram num processo de "crise de identidade". A consequência disso está no cerne das transformações de produção de bens e de saberes que provocam uma espécie de cansaço existencial do sujeito (fragmentado, contraditório, deslocado, descentrado), fazendo surgir o conceito de sujeito pós-moderno. (IDEM, 2013, p. 2).
\end{abstract}

Notamos, portanto, tanto em Benjamim como nos autores há pouco citados que a narrativa, ou melhor, a forma de narrar está relacionada com o contexto no qual o sujeito está inserido. A influência cultural apresenta-se como um dos pontos transformadores nas narrativas. E se no pós-guerra, uma vez influenciados pelos meios de comunicação, as narrativas entraram em declínio, na contemporaneidade elas se apresentam de forma distinta a partir dos meios técnicos disponibilizados a quem se propõe a narrar. Dentre tantas outras formas de narrar, a que os jovens da pesquisa apresentam é descontínua e surge freneticamente em framers nas mídias digitais.

A rede social como dispositivo em que se faz sujeito ao se configurar a relação homem-máquina tangencia para uma discussão pertinente acerca da literatura ali formatada pelas minorias. A narrativa construída no canal digital pelos jovens da periferia pode ser vista/pensada como literatura menor (DELEUZE \& GUATARRI, 1977), já que vigora nesta discussão o uso que a minoria faz em uma língua maior. Ou seja, há uma desterritorialização por parte dos jovens da periferia do espaço digital hegemônico ao debater questões pertinentes à sua realidade marginalizada. Para tanto, vale trazer um trecho da terceira característica da literatura menor (tudo adquire um valor coletivo) para ajudar a entender a repercussão das narrativas periféricas entre os pares. 
O que o escritor sozinho diz, já constitui uma ação comum, e o que o escritor sozinho faz, é necessariamente político, ainda que os outros não estejam de acordo [...] é a literatura que se encontra escorregada positivamente desse papel e dessa função de enunciação coletiva, e mesmo revolucionária: é a literatura que produz uma solidariedade ativa, apesar do ceticismo; e se o escritor está à margem ou afastado de sua frágil comunidade, essa situação o coloca ainda mais em condição de exprimir uma outra comunidade potencial, de forjar os meios de uma outra consciência e de uma outra sensibilidade (p. 27).

O eu que narra sua vida no ciberespaço assume a responsabilidade do que divulga, mesmo que o entendimento do outro seja dissonante com o que objetiva. Ali o que pesa é preponderantemente seu interesse em publicizar, mais do que se fazer entender. A escrita tal qual a percepção aparente individualidade de ideias nos perfis de cada usuário. Contraditoriamente a rede social se faz individual no coletivo. $O$ indivíduo acredita estar num espaço privado, discorrendo sobre suas intimidades, relatando individualidades, produzindo subjetividades que disparam diante de todos nós.

As imagens também surgem como narrativas de si na contemporaneidade. Baudrillard (1991) acredita que em uma era na qual a mídia de massa está em toda a parte, cria-se uma nova realidade, hiper-realidade composta pelo amalgamamento do comportamento das pessoas com as imagens exibidas pela mídia. Para o autor, o mundo da hiper-realidade é feito de simulacros imagens cujo significado só pode ser revelado a partir de outras imagens e que, por isso, não possuem nenhum embasamento em uma 'realidade externa'.

No contexto social contemporâneo, as imagens mais que os textos, refletem substancialmente aquilo que pretendem comunicar. Os jovens da periferia, enquanto usuários das redes sociais, participam ativamente da troca de imagens de si mesmos. Suas postagens vão desde autorretratos feitos em casa, num ambiente íntimo, até cartazes de eventos que discutem problemáticas sociais em que participaram ou participarão. Nota-se, portanto, que o compartilhamento de imagens que demonstra preocupação política-social é a forma que encontram em estar atuando sem dispensar fotografias do privado.

A influência mercadológica na proliferação de imagens pessoais nas redes sociais é reflexo do "fetichismo da mercadoria" de que fala Karl Marx. A mercadoria neste contexto é a própria imagem do sujeito onde "as pessoas agem como coisas e as coisas, como pessoas". 
Pontos de Interrogação, v. 4, n. 1, jan./jun. 2014

Revista do Programa de Pós-Graduação em Crítica Cultural

Universidade do Estado da Bahia (UNEB), Campus II - Alagoinhas - BA

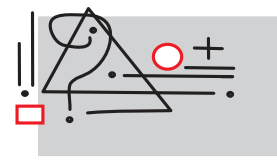

pontos de interrogação

Nesse "mercado de personalidades", em que a própria vida, se torna uma mercadoria pronta para o consumo, a imagem pessoal adquire o principal valor de troca (SIBILIA, 2008).

No caso dos jovens da pesquisa, a mercadoria imagética não está presente apenas na imagem pessoal, mas na pessoa vinculada ao trabalho que realiza frente aos grupos sociais. Quando publicam imagens concedendo entrevistas, em ações que divulgam os trabalhos ou em iniciativas do próprio grupo que estão vinculados, não é apenas sua imagem que está na "vitrine" digital, como também a do trabalho que fazem e da periferia onde moram. É dessa forma que conquistam a repercussão que faz engrandecer suas ações.
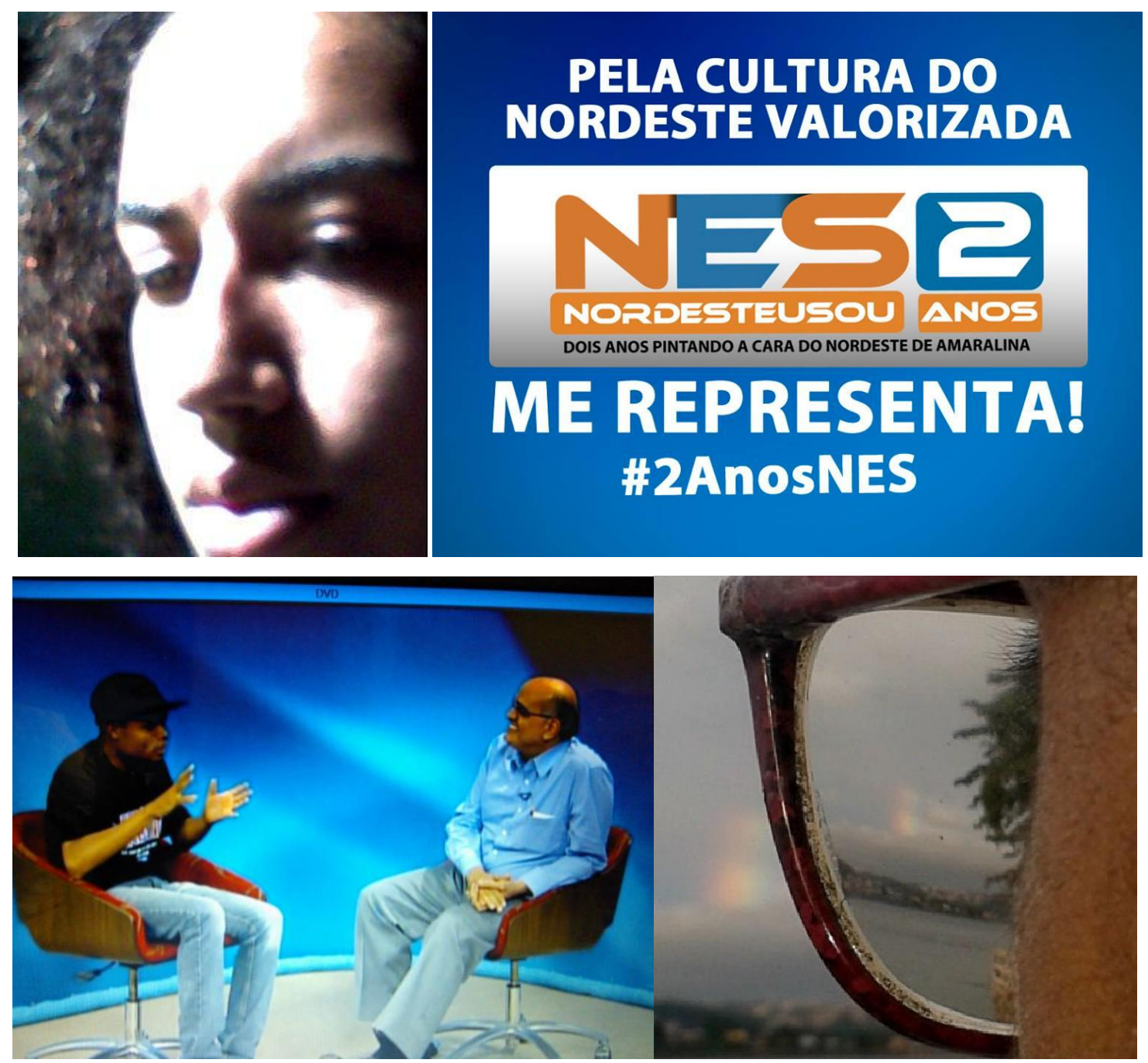
Ao ver o mundo como um espelho do eu, a personalidade narcísica de nossos dias ancora-se na autopromoção e investe na aparência como recursos estratégicos que visam cativar os olhares alheios que miram o show do eu (LASCH, 1983, SIBILIA, 2008b, 2010). As imagens postadas nas redes sociais não deixam de ser publicidade de si e a medição dos efeitos também se dá por números, mas estes são de comentários e curtidas.

Diante de toda profusão de imagens pessoais e todas as mudanças nas práticas sociais, é possível perceber que estamos perante a mais nova forma de fetiche, a "fetichização visual" (CANEVACCI, 2008). Para o autor, esse fetiche se difunde na relação entre os corpos e espaços panorâmicos espalhados nas metrópoles comunicacionais. Tais composições fetichistas são divulgadas por meio de contínuas manifestações de comunicação visual, consumos performáticos, múltiplos sujeitos, sincretismos digitais, difusão sound-scape. Os fetichismos visuais estão ligados à difusão tanto de tecnologias digitais quanto de estilos corporais.

Dessa forma, as redes sociais são também um espaço de padronização de identidades. Mesmo que fluida e instantânea, há um interesse na reprodução do que ocorre em outras culturas. Rolnik (1997) alerta que para além de uma identidade há uma subjetividade na qual o indivíduo se reconhece como aquilo que é, é algo movente, poroso às mudanças ou não a depender da configuração histórico-social em que o indivíduo se encontre.

A mesma globalização que intensifica as misturas e pulveriza as identidades implica também na produção de kits de perfis-padrão de acordo com cada órbita do mercado, para serem consumidos pelas subjetividades, independentemente de contexto geográfico, nacional, cultural etc. identidades locais fixas desaparecem para dar lugar a identidades globalizadas flexíveis, que mudam ao sabor dos movimentos do mercado e com igual velocidade. (p. 20).

Diante disso, os recursos das redes sociais servem de aporte para o consumo das subjetividades lhes dando um modelo muitas vezes parecido. Mesmo quando a vontade é ser diferente, os sujeitos terminam por se encontrarem em espaços que as identidades se cruzam e se assemelham. Ao passo que buscamos reconhecer a diversidade, o movimento intercultural relação de troca entre os grupos - nos coloca diante de um enquadramento mercadológico e fetichista, que sem perceber, nos tornam iguais, mas paradoxalmente, são excludentes. 
Imagens que se aglomeram conjuntamente nas telas de vidro e que passam a mediar as relações sociais perpassadas, prioritariamente na atualidade, pelos media. Ao deslocarem o eixo de dentro de si para tudo aquilo que pode ser visto, admirado e contemplado pelos outros, as subjetividades podem forjar-se exteriormente, migrando de um caráter introdirigido para um caráter alterdirigido. Produzindo-se como eus visíveis e eus espetaculares (SIBILIA, 2008), então as personalidades narcísicas deixam que os outros vejam aquilo que mostram, de modo que, para existirem, precisam ser vistas.

Os relatos de vida encontrados nas redes sociais podem ser considerados obras onde é possível perceber múltiplas construções de si que vão se configurando de acordo com o objetivo do sujeito. Guatarri e Rolnik (1986) ao analisarem os processos de subjetividade, afirmam que os mesmos não se dão por centralização ou por semiotização, tampouco são exercidos por agentes individuais ou grupais. Estes autores apostam antes em seu funcionamento rizomático e em sua dimensão maquínica:

... [eles] implicam o funcionamento de máquinas de expressão que podem ser tanto de natureza extrapessoal, extra-individual (sistemas maquínicos, econômicos, sociais, tecnológicos, icônicos, ecológicos, etológicos, de mídia, enfim, sistemas que não são mais imediatamente antropológicos), quanto de natureza infra-humana, infrapsíquica, infrapessoal (sistemas de percepção, de sensibilidade, de afeto, de desejo, de representação, de imagens, de valor, modos de memorização e de produção idéica, sistemas de inibição e de automatismos, sistemas corporais, orgâ- nicos, biológicos, fisiológicos, etc.) (p. 31).

Os processos de subjetivação produziram composições feitas de hibridismos, pensados não apenas na produção cultural, mas também da subjetividade não submetida a um princípio identitário, conforme afirma Rolnik (1998). Há uma virtualidade permanente nos processos subjetivos que se atualizam em diferentes contornos não apreensíveis numa figura identitária. Para além de uma identidade suposta, estão em curso processos de subjetivação inapreensíveis por ela.

As redes sociais induzem os usuários a apresentarem sua vida como melhor que a dos outros. Uma felicidade, por vezes forjada, porém desejada. "Na raiz de todo dispositivo, está deste modo, um desejo demasiadamente humano de felicidade, e a captura e a subjetivação deste desejo, numa esfera separada, constituem a potência específica do dispositivo" 
(AGAMBEN, 2009, p. 44). Nessa desenfreada disputa, as redes se potencializam, capturam usuários atingindo-lhe o desejo em ser único diante de milhares.

\section{3 - IMAGENS E POSTAGENS: UMA ANÁLISE DAS PUBLICAÇÕES}

Para quem utiliza as redes sociais como mais um (ou único) espaço de interação, torna-se rotineiro a visita diária nos perfis visando à socialização virtual por quem compõe a rede ou o uso simplesmente da "informação" sobre o que de novo os amigos virtuais têm compartilhado. Uma ação cotidiana que pode ser realizada em qualquer outro espaço físico aliada a outras ações tão rotineiras como a visita virtual. Este deslocamento frequente para o mundo virtual do sujeito contemporâneo permite-nos trazer a discussão estabelecida por Michel de Certeau (1998) em a Invenção do Cotidiano.

Em seus estudos, Certeau centra-se no sujeito como alguém que utiliza e se apropria dos produtos da cultura de massa de forma a atender sua necessidade através de ações que ele conceitua como táticas, mascarando-se numa aparente conformidade. Ou seja, o sujeito - na definição do autor, o usuário- não enfrenta as ações das instituições - as estratégias. Para Certeau estratégia é o cálculo (ou a manipulação) das relações de forças que se torna possível a partir do momento em que um sujeito de querer e poder (uma empresa, um exército, uma cidade, uma instituição científica) pode ser isolado.

A estratégia postula um lugar suscetível de ser circunscrito como algo próprio e ser a base de onde se podem gerir as relações com uma exterioridade de alvos e ameaças (os clientes ou os concorrentes, os inimigos, o campo em torno da cidade, os objetivos e objetos de pesquisa e etc) como na Administração de empresas, toda racionalização "estratégica" procura em primeiro lugar distinguir de um "ambiente" um "próprio, isto é, o lugar do poder e do querer próprios (CERTEAU, 1998, p. 99).

O usuário, portanto, se vale de táticas para desviar das imposições estratégicas se beneficiando do que ela tem a lhe oferecer. Ele extrai o que melhor atende suas necessidades por reconhecer sua ausência de poder.

Ela (tática) não tem portanto a possibilidade de dar a si mesma um projeto global nem de totalizar o adversário num espaço distinto, visível e objetivá- 
vel. Ela opera golpe por golpe, lance por lance. Aproveita as "ocasiões" e delas depende, sem base para estocar benefícios, aumentar a propriedade e prever saídas. O que ela ganha não se conserva. Este não-lugar lhe permite sem dúvida mobilidade, mas numa docilidade aos azares do tempo, para captar no voo as possibilidades oferecidas por um instante (...). Em suma, a tática é a arte do fraco (IDEM, p. 100-101).

Enxergando os usuários das redes sociais, sobretudo os jovens em questão, como sujeitos que através de táticas específicas conseguem utilizar o dispositivo como difusor de realidades escamoteadas pelas grandes mídias, notamos características dos sujeitos que convergem com as citadas por Certeau há alguns anos. Os usuários das redes conservam sua diferença num espaço onde "dominador" e "dominado" se encontram. Utilizando-se dos elementos oferecidos pelo ambiente virtual, os jovens trazem à cena discussões e problemáticas que os próprios sujeitos incorporados às estratégias criam e/ou colaboram para sua permanência.

Sem transgredir as leis impostas pelo espaço que estão inseridos, os jovens não se definem por elas. Eles desviam daquilo que lhes são impeditivos e criam seu próprio lugar de fala, abrindo um grande canal de comunicação e interação entre pessoas que vivem realidades parecidas e entre pessoas que sequer buscam informar-se sobre estas realidades além do que é propagado pelos meios dominantes.

Foi utilizando a rede social como meio de ascensão social e cultural, e não como objeto de crítica, que Enderson Araújo conseguiu mudar sua história e dar projeção à comunidade de Sussuarana entre as pessoas que fazem parte da sua rede virtual de convivência. Mudança que ele relata no post publicado em 23 de Agosto de 2013.

Três anos atrás, eu era só um garoto que ganhava meio salário para varrer rua e cuidar de jardim, hoje sou um jovem que ocupo um monte de espaço e sou referência para muitos outros', palavras minhas depois de uma noite que eu consegui perder as palavras.

O momento a que Enderson se refere é o da sua participação no Programa Aglomerado da Central Única das Favelas (CUFA) exibido pela TV Brasil. Entre as diversas fotos que publicou em sua timeline estão fotos tiradas no momento da sua participação que contou com a presença dos cantores Arlindo Cruz e MV Bill. 
Pontos de Interrogação, v. 4, n. 1, jan./jun. 2014

Revista do Programa de Pós-Graduação em Crítica Cultural

Universidade do Estado da Bahia (UNEB), Campus II - Alagoinhas - BA

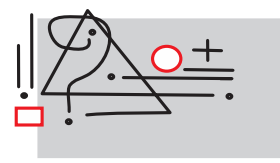

A satisfação em fazer parte de um grupo de pessoas que discutem a periferia em outros espaços que não apenas o da sua convivência é evidente nas palavras e imagens compartilhadas em seu perfil. Ao dividir esses momentos com todos que fazem parte da rede, Enderson não só diz: "eu consegui", mas também anuncia: "você também pode ser a diferença".
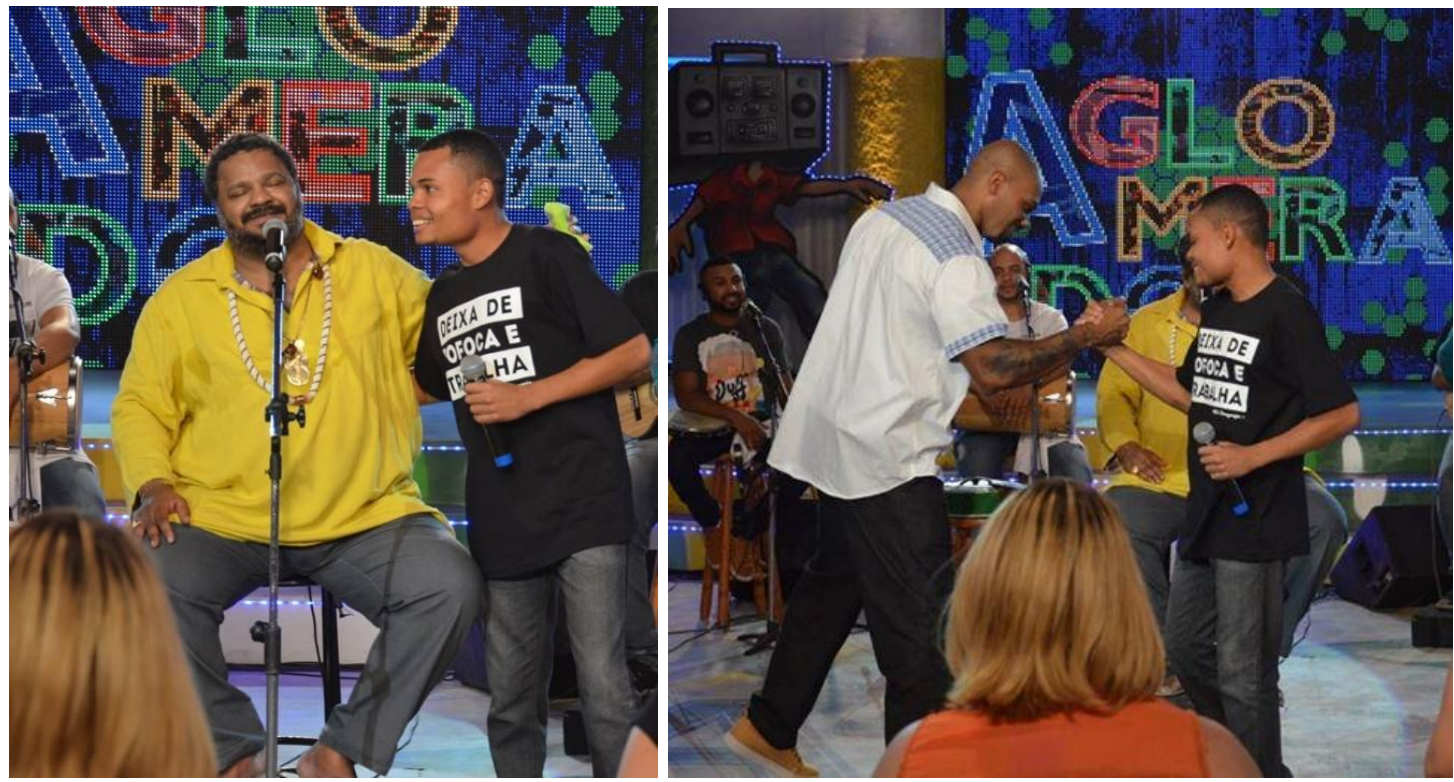

Ao analisar suas publicações e compartilhamentos, percebe-se que sua pretensão não é apenas relatar a condição estrutural da comunidade periférica, nem simplesmente expor histórias de pobreza e dificuldade dos periféricos, mas principalmente, mostrar aos jovens que é possível criar formas de acesso e táticas nos usos dos dispositivos que viabilizem uma trajetória diferente das (pré) estabelecidas por quem nasce e vive numa classe social com poucas oportunidades.

Enderson Araújo também é responsável por uma página virtual, mas suas opiniões e pensamentos são mais firmes e fundamentados quando se trata de discussões sociopolíticas. A atuação de Enderson diante das problemáticas que circundam a periferia se dá por meio do diálogo e debates políticos com organizações e pessoas envolvidas em diversos projetos Brasil afora. Essas experiências enriquecem seu discurso e o faz assumir um posicionamento crítico consciente do objetivo que pretende atingir com as elucubrações investidas no perfil sem cair na dubiedade e na divergência de ideias. 
Poderíamos afirmar, usando as palavras de Goffman, que Enderson se encaixaria na denominação do que seria o "ator disciplinado". Segundo o autor, este tipo de ator é alguém dotado de autocontrole que consegue suprimir sua resposta emocional a seus problemas pessoais, aos companheiros quando cometem erros e à plateia quando instiga sentimentos adversos ou hostilidade para com ele. O ator disciplinado, portanto, sabe como se comportar e se fazer entender diante de grupos diversos sem comprometer sua performance e, sobretudo, sem afetar a imagem que criou de si diante deles.

A definição do ator disciplinado pode ser exemplificada no seguinte post feito por Enderson no dia 27 de agosto. "Então vc desce do ônibus, e adentra a comunidade, o cara lá do outro lado grita: Ei, Anderson, estou acompanhando o trabalho, ta ficando lindo, isso aí, representa nós lá... A cabeça começa a doer, a responsabilidade é enorme”. Mesmo sem uma cobrança direta, Enderson precisa atender as expectativas que ele mesmo gerou ao iniciar os trabalhos com o Mídia Periférica e que pretende retribuir seja na sua comunidade seja em outras cidades, dentro e fora da Bahia.

Saindo aqui da sede da Cufa na Borneo em Madureira e vou caminhando e observando, o quanto foi precioso estar essa uma semana aqui, aprendendo com cada um, enfim, sou meio emotivo com certas coisas, e não sou bom com despedidas, mas creio que em alguns anos próximos essa galera que me recebeu aqui de braços abertos, vai sentir orgulho em ter colaborado para minha formação. Fui! (24 de agosto de 2013).

O espaço midiático de interação criado por esses jovens é uma forma de divulgação onde apresentam uma periferia diferente da retratada midiaticamente e desconhecida pela classe hegemônica. Para além de uma mídia reguladora, onde "a esfera pública de visibilidade midiática exerce o papel de reguladora entre a relação dos indivíduos com o mundo e com seus pares" (PAIVA apud SILVA, 2009, p.66), os jovens querem uma mídia que desconstrua estereótipos da periferia e de seus moradores difundidamente estigmatizados.

Eles reconhecem a importância da "visibilidade midiática" (SILVA, 2009, p.66), tanto que fazem uso dela para a difusão de ideias, porém através de meios alternativos de comunicação, pois o espaço que a periferia encontra nas grandes mídias é para a espetacularização do contexto social. "A emergência de novos modelos de participação social propiciada pelo ad- 
vento das inovações tecnológicas pode revelar novas formas de atuação comunitária, (...) elaborados por grupos minoritários.” (IDEM, p.67)

"Com toda certeza, as redes sociais são uma forma muito direta de você expor sua opinião e ter um retorno rápido quanto a ela", é o que acredita a jovem Liege Viegas, cujas publicações no mês de junho estavam relacionadas às manifestações, atendendo assim, um anseio dos jovens que fazem parte da sua rede de relacionamento em ver/ouvir/publicar/discutir o tema do momento. Para Goffman, Liege não estaria exercendo nada menos do que exige sua representação bem sucedida, ou seja, ela apresenta o tipo de cena que leva a cabo os estereótipos extremos dos observadores.

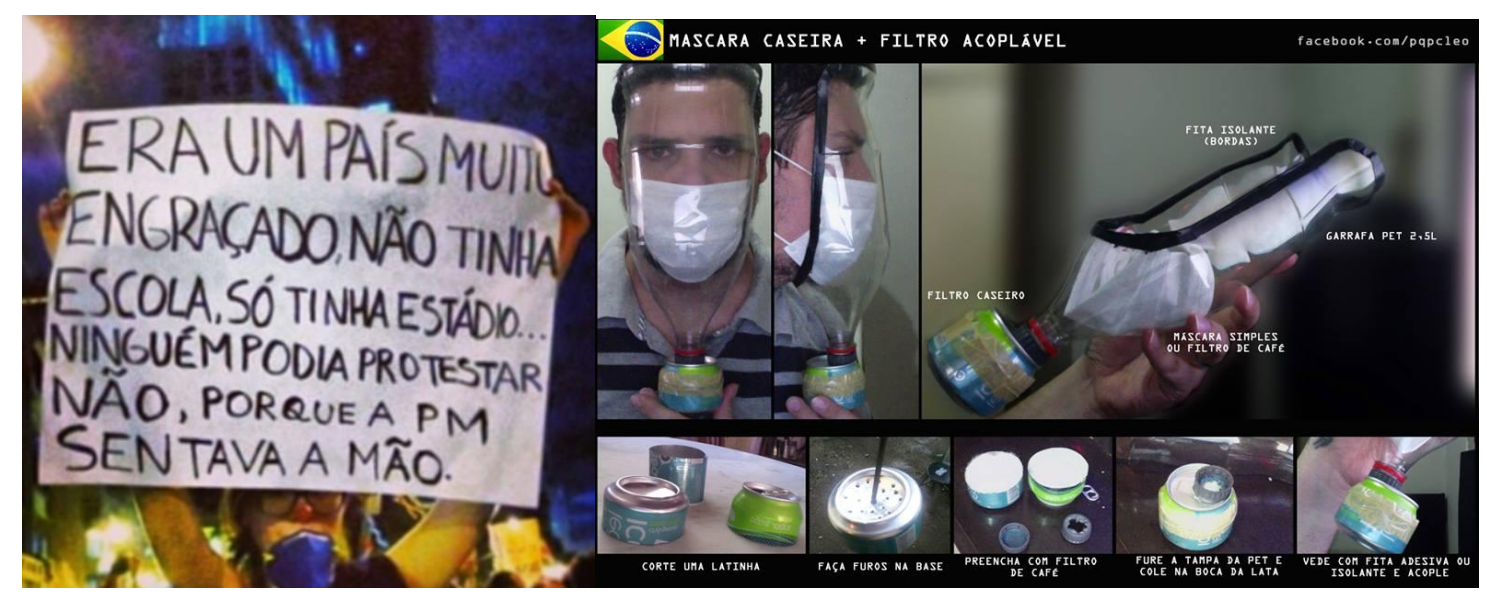

Como um tático que se manifesta não em seus produtos, mas na sua metodologia Liege se beneficia da publicação de imagens para atrair olhares e participação naquilo que posta. "Quando se publica textos a participação é bem pequena, talvez pela preguiça de ler (o que é um grande problema), porém se é um vídeo ou alguma charge a recepção é muito boa. As imagens vinculadas a um texto curto e simples surtem um efeito bem positivo". Por outro lado ela também acredita que levantar questões é a forma mais atraente de provocar a participação do outro, mesmo que esta seja inexpressiva. "Fazer fervilhar a mente em busca de interrogações. Sim, interrogações. Por que se você deixa de perguntar estará acomodado”.

O fracasso no retorno da tática de Liege se dá por uma falta de participação efetiva no dispositivo. O uso que faz da rede social se dá de modo esporádico sem qualquer preocupação em retroalimentar e repercutir aquilo que publica. Tática que os outros jovens costumam adotar com mais eficiência. Estas ações se dão quando curtem o comentário feito por terceiro, 
Pontos de Interrogação, v. 4, n. 1, jan./jun. 2014

Revista do Programa de Pós-Graduação em Crítica Cultural

Universidade do Estado da Bahia (UNEB), Campus II - Alagoinhas - BA

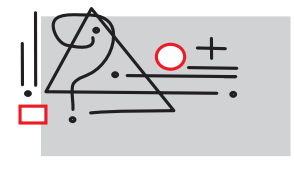

quando estabelece um diálogo neste espaço e quando marcam pessoas interessadas naquela publicação que, por algum motivo não tenha se atentado para o texto primeiro.

Mais importante do que perceber o que agenciava as publicações sobre aspectos sociais nacionais, era preciso também perceber o que sobre as comunidades onde moram os jovens diziam. Longe de uma frequência esperada, as publicações dos jovens sobre a comunidade onde moram variavam entre alguns registros e divulgação de ações realizadas nos bairros por meio dos grupos que fazem parte. Havia algumas publicações de prestação de serviço como vagas de emprego em Sussuarana, por Liege Viegas e a seleção de novos jovens colaboradores para o Mídia Periférica, por Enderson Araújo.

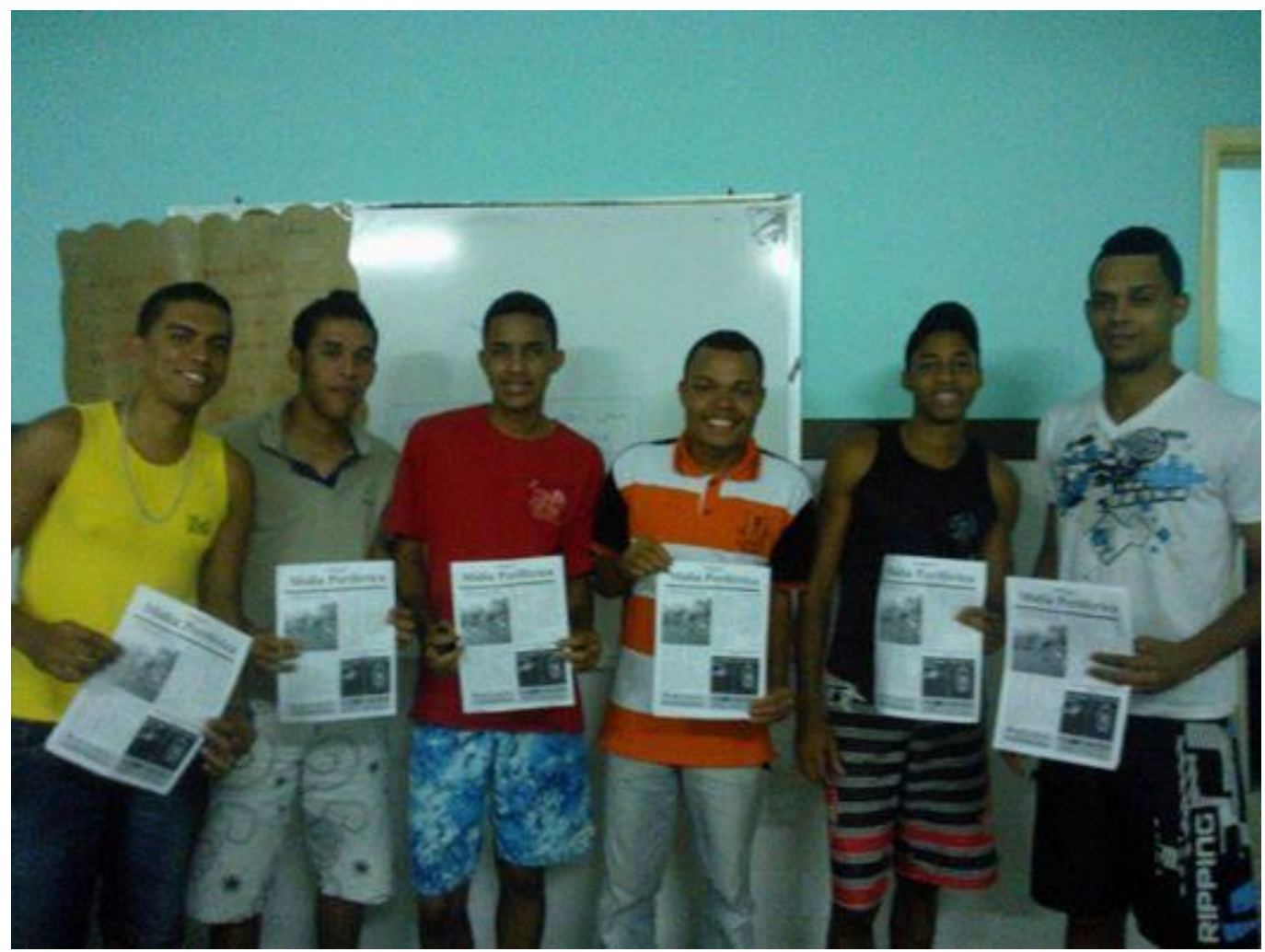

Jovens selecionados para compor o Mídia Periférica. Imagem publicada no dia 13 de junho de 2013.

A desigualdade social está implícita em quase todas as publicações dos jovens, tanto nas publicações sobre as manifestações, quanto em publicações cotidianas. Dessa forma, os jovens marcam sua posição de fala, deixando claro que aquele espaço virtual, mesmo congregando classes diversas, também é um meio divulgador da sua realidade para conhecimento 
coletivo. A periferia pode não protagonizar todas as suas publicações, mas está orgulhosamente presente em citações veladas e expressões silenciosas.

Porta-vozes das comunidades, mesmo não se colocando nesta posição, os jovens descobriram que a internet é a melhor forma de desconstruir o que foi perpetuado no imaginário coletivo sobre a periferia. Os perfis pessoais da rede social podem não parecer, para alguns, como este espaço da desconstrução de estereótipos, mas o espaço virtual foi o ambiente que escolheram para ver a mudança acontecer quando criaram páginas onde têm direito a vez e fala.

\section{CONCLUSÃO}

O espaço virtual adquire na contemporaneidade um outro lugar social paralelo ao offline onde nos transportamos várias vezes ao dia, alguns por hora seguidas, a fim de estabelecer relações impossibilitadas por diversas circunstâncias. A fronteira do tempo-espaço é diluída no ciberespaço, proporcionando interações, acessos e conhecimentos sem obstáculos. As redes sociais aparecem como um ambiente facilitador das relações interpessoais reunindo pessoas afastadas por motivos eventuais, bem como criando novas redes de contato entre indivíduos que não se conhecem.

A facilidade de acesso gerada pelo avanço tecnológico contribui para que indivíduos que não tinham condições de adquirir determinados bens tecnológicos encontrassem em outras opções formas de se verem conectados. A multifuncionalidade de um aparelho celular é uma das transformações que mais resultou no aumento significativo de usuários da internet, sobretudo das redes sociais.

Uma vez impossibilitados em manter-se conectados virtualmente através de computadores por demandar custos consideráveis, (aquisição do computador, contratar serviços de internet de banda larga, além de gastos relacionados ao uso de computadores, como aumento no consumo de energia) os jovens, principalmente os de baixa renda, encontraram no aparelho celular a mais usual, senão única, via de acesso ao espaço virtual.

Valendo-se do impacto transformador que as redes sociais provocaram nas práticas sociais dos jovens contemporaneamente, este trabalho se propôs a analisar seis perfis de jovens 
Pontos de Interrogação, v. 4, n. 1, jan./jun. 2014

Revista do Programa de Pós-Graduação em Crítica Cultural

Universidade do Estado da Bahia (UNEB), Campus II - Alagoinhas - BA

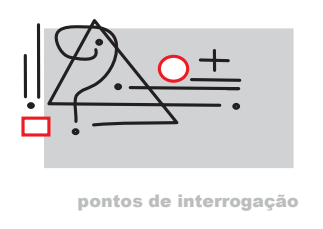

da periferia que fazem uso dessa plataforma de comunicação em seus cotidianos de forma a apontar o que pautaram esses jovens no jogo mútuo das representações de si em rede.

Faz-se necessário pensar a rede social como o espaço onde as publicações são plasmadas diante de olhos curiosos. No âmbito da repercussão é inegável a dimensão que as postagens atingem no espaço virtual comparada a outros meios de comunicação. Por esta dimensionalidade a internet é caracterizada como um lugar desterritorializado que se desdobra em outra característica a do espaço democrático.

Essa noção leva-nos a creditar o espaço virtual como um lugar onde impera o direito de fala e de expressão a todos, sem um moderador que impossibilite a transmissão de ideias. Contudo o próprio meio técnico mostra-se vigilante diante do que é publicado. Ao fazer parte de determinados espaços virtuais, somos levados a aceitar a regulamentação imposta, sujeitos a deixar de compor as páginas virtuais caso as regras pré-estabelecidas sejam descumpridas.

No espaço virtual o conceito de democracia engendra novas concepções vigorando a ideia usual de um lugar onde todos podem se manifestar. Assim, os jovens da pesquisa repercutem esta ideia por não encontrarem dificuldades em efetivar suas publicações. O que está em questão, quando questiono a democracia nas plataformas digitais, não é permitir o uso irresponsável da internet, principalmente para a realização de crimes virtuais e qualquer tipo de abuso que ultrapasse o direito e o respeito aos outros usuários, mas é oportunizar questões que problematize esta dita democracia para além de uma definição generalizada.

Ao encontrarem nas páginas virtuais um lugar de fala, em que lhes é dado visibilidade e reconhecimento, os jovens na verdade estão potencializando o uso limitado que determinados espaços contêm. Ao replicarem as páginas virtuais do Mídia Periférica e do NORDESTeu$S O U$ no Facebook, os jovens deixam escapar que a dimensionalidade ali não está sendo suficiente. Limitações de acesso, de ferramentas, dificuldades na interação sinalizam para uma fragilidade na comunicação e, portanto, no seu alcance.

Mas não são apenas as limitações estruturais que desestabiliza a democracia virtual. Enquanto espaços mercantilizados, os espaços virtuais colocam seus usuários como mercadorias que precisam atrair cada vez mais usuários/mercadorias a fim de retroalimentarem todo mercado virtual que cresce substancialmente. Diante desta lógica mercadológica nos vemos cercados por publicidades e sujeitados à atração que sites e páginas virtuais tentam provocar nos 
usuários das redes sociais. Valendo-se para isso da espetacularização dos indivíduos e do abuso que é feito das imagens.

Há quatro décadas, quando Debord deu a conhecer suas reflexões, ainda estava se delineando no horizonte a espetacularização do mundo que agora vivenciamos com tanto estrépito. Por isso são tão valiosas suas observações acerca das relações que se mercantilizam ao ser mediadas por imagens; bem como a passagem do ser para o ter, e deste último para o parecer, deslizamentos que acompanham a ascensão de um tipo de subjetividade cada vez mais espetacularizada, o triunfo de um modo de vida inteiramente baseado nas aparências e a transformação de tudo em mercadorias. (SIBILIA, 2008, p. 268).

Pode parecer que em nada somos atingidos quando o que pesa no sentido da democracia virtual é a possibilidade de manifestar-se. Mas é preciso perceber que esse direito é consentido e não conquistado. Consente-se o direito de fala, mas se o que estiver expresso gerar incômodo a terceiros, abre-se uma denúncia e a publicação pode ser retirada sem qualquer aviso prévio. Não apenas a publicação, mas perfis e fan pages são monitorados e estão sujeitos a serem excluídos pelo técnico.

Alguns perfis analisados buscam apresentar em seus espaços uma periferia diferenciada da comumente retratada, extraindo beleza no aglomerado de casas ou mesmo do cotidiano dos seus moradores e das belezas naturais que se impõem em meio a selvageria dos concretos e a desorganização urbana. Durante o tempo que se seguiu de pesquisa foi possível perceber que para além de uma tentativa em desconstruir o imaginário já estabelecido da periferia marginalizada, estes jovens estavam dedicados em discutir os problemas com quem nela vive a fim de desviarem dos obstáculos impostos.

O que se percebe nos jovens é que eles acreditam na democracia virtual por encontrarem nela a possibilidade de expressão não consentida em outros espaços. Por meio daquilo que lhes é proporcionado os jovens publicam imagens e textos que favorecem na repercussão dos trabalhos que desenvolvem em outros espaços virtuais. A despeito de possíveis fracassos na propagação das publicações em seus perfis, os jovens ainda assim utilizam a rede social para reclamar problemas situacionais; propagar suas atividades e, sobretudo, para reverberar a emergência de um olhar menos preconceituoso para com a periferia e seus moradores.

Afora qualquer critério de valor que possa revestir as publicações dos jovens da periferia, o que esteve em curso nessa pesquisa foi a oportuna utilização das redes sociais como 
espaço de fala. Realidades desdobradas em diminutas narrativas e convertidas em imagens fragmentadas que mais do que evidenciar subjetividade construída na visibilidade, saltavam às vistas representações de si numa encenação cotidiana.

Foi possível considerar, por fim, que o processo de representação de si no ciberespaço é heterogêneo. Neste processo há tanto aqueles que buscam criar um si que expresse suas experiências sociais, de luta, emocionais, estéticas, entre outras, como aqueles que se conformam às expectativas das comunidades às quais se integram, como ainda aqueles que tentam se ocultar atrás de uma personagem, que pouco ou nada expõe de si.

\section{REFERÊNCIAS}

AGAMBEN, Giorgio. O que é o contemporâneo? E outros ensaios; Tradução Vinícius Nicastro Honesko. - Chapecó, SC: Argos, 2009.

BAUDRILLARD, Jean. Simulacros e simulação. Lisboa: Relógio D’Água, 1991.

BENJAMIN, Walter. A obra de arte da era de sua reprodutibilidade técnica. In: Obras Escolhidas, v.1, Magia e técnica, arte e política, trad. S.P Rouanet, São Paulo: Brasiliense, 1985.

BENJAMIN, Walter. O Narrador: considerações sobre a obra de Nikolai Leskov.In: Magia e técnica, arte e política: ensaios sobre literatura e história da cultura. São Paulo: Brasiliense, 1994, p. 197-221.

BRETHERICK, Giselda Geronymo Sanches. Desterritorialização do conhecimento e descentralização do saber na obra de Pierre Lévy. In. Revista Múltiplas Leituras, v. 3, n. 1, p. 184196, jan. jun. 2010.

CANEVACCI, Massimo. Fetichismos visuais: corpos eropticos e metropole comucacional. São Paulo: Ateliê Editorial. 2008

CARNEIRO, Vanderlei \& MATTES, Marlene Gonçalves. Linguística e Filosofia: redefinindo o conceito de narrativa contemporânea. Texto extraído do site em 15 de agosto de 2013.

CERTEAU, Michel. A Invenção do cotidiano: 2. Morar. Cozinhar/ Michel de Certeau, Luce Giard, Pierre Mayol; tradução de Ephraim F. Alves e Lúcia Endlich Orth. - Petrópolis, RJ: Vozes, 1996.

DELEUZE, Giles \& GUATARRI, Félix. Mil platôs:capitalismo e esquizofrenia. Vol. 1.Tradução Aurélio Guerra Neto e Célia Pinto Costa. Rio de Janeiro: Ed. 34, 1995. 
FOUCAULT, Michel. A Ordem do discurso. 21 ${ }^{\text {a }}$ Edição. São Paulo, Loyola, 1996.

FOUCAULT, Michel. Vigiar e Punir; Nascimento da Prisão. Tradução Raquel Ramalhete. Petrópolis, Vozes, 1987.

FREITAS, Ricardo Oliveira de. A periferia da periferia: mídias alternativas e cultura de minorias em ambientes não-metropolitanos. In. Cadernos de Ciências Humanas - Especiaria. v. 10, n.17, jan./jun., 2007, p. 191-212.

GOFFMAN, Erving. A representação do eu na vida cotidiana. Tradução de Maria Célia Santos Raposo. Petrópolis, Vozes, 1985.

GUATTARI, Félix \& ROLNIK, Suely. Micropolítica - Cartografias do desejo. 2. ed. Petrópolis: Vozes, 1986.

HAESBAERT, Rogério. O mito da desterritorialização. Rio de Janeiro: Bertrand Brasil.

HAESBAERT, Rogério \& BRUCE, Glauco. A Desterritorialização na obra de Deleuze e Guattari. Disponível em

http://www.uff.br/geographia/ojs/index.php/geographia/article/viewArticle/74 Capturado em 09 de setembro de 2013

JENKINS, Henry. Cultura da Convergência. São Paulo: Aleph, 2009.

LÈVY, Pierre. Cibercultura. São Paulo, Ed. 34, 1999.

MARX, Karl; ENGELS, Friedrich. Manifesto do Partido Comunista. Belo Horizonte: Liga Operária e Camposena, 1998.

ROLNIK, Suely. Cultura e subjetividade: Saberes nômades/Daniel S. Lins (Org). - Campinas, SP: Papirus, 1997.

SIBILIA, Paula $O$ show do eu: a intimidade como espetáculo/Paula Sibilia. - Rio de Janeiro: Nova Fronteira, 2008.

SILVA, Célia Regina da. Lágrimas e Punho: (in)visibilidade, dor e humanidade na esfera pública de visibilidade midiática. In. Mídia Alternativa: Estratégias e desafios para a comunicação hegemônica/Organizador Ricardo O. Freitas. - Ilhéus, BA: Editus, 2009.

UWE, Flick. Introdução à pesquisa qualitativa; tradução Joice Elias Costa. - 3. Ed. - Porto Alegre: Artmed, 2009.

Recebido em: 25 de março 2014. Aprovado em: 15 de abril de 2014. 